\title{
Guidelines for Nonvariceal Upper Gastrointestinal Bleeding
}

\author{
Joon Sung Kim ${ }^{1}$, Byung-Wook Kim¹, Do Hoon Kim², Chan Hyuk Park ${ }^{3}$, Hyuk Lee ${ }^{4}$, Moon Kyung Joo ${ }^{5}$, Da Hyun Jung ${ }^{6}$, Jun- \\ Won Chung ${ }^{7}$, Hyuk Soon Choi ${ }^{5}$, Gwang Ho Baik ${ }^{8}$, Jeong Hoon Lee ${ }^{2}$, Kyo Young Song ${ }^{9}$, and Saebeom Hur ${ }^{10}$, The Korean \\ Society of Gastroenterology, Korean College of Helicobacter and Upper Gastrointestinal Research, Korean Society of \\ Gastrointestinal Endoscopy, The Korean Gastric Cancer Association, Korean Society of Interventional Radiology
}

${ }^{I}$ Department of Internal Medicine, College of Medicine, The Catholic University of Korea, ${ }^{2}$ Department of Gastroenterology, Asan Medical Center, University of Ulsan College of Medicine, Seoul, ${ }^{3}$ Department of Internal Medicine, Hanyang University Guri Hospital, Hanyang University College of Medicine, Guri, ${ }^{4}$ Department of Medicine, Samsung Medical Center, Sungkyunkwan University School of Medicine, ${ }^{5}$ Department of Internal Medicine, Korea University College of Medicine, ${ }^{6}$ Department of Internal Medicine, Yonsei University College of Medicine, Seoul, ${ }^{7}$ Department of Internal Medicine, Gachon University Gil Medical Center, Incheon, ${ }^{8}$ Department of Internal Medicine, Hallym University College of Medicine, Chuncheon, ${ }^{9}$ Department of Surgery, College of Medicine, The Catholic University of Korea, and ${ }^{10}$ Department of Radiology, Seoul National University College of Medicine, Seoul, Korea

Nonvariceal upper gastrointestinal bleeding (NVUGIB) refers to bleeding that develops in the gastrointestinal tract proximal to the ligament of Treitz. NVUGIB requires hospitalization and is associated with significant morbidity and mortality. Although European and Asian-Pacific guidelines have been published, there have been no previous guidelines regarding management of NVUGIB in Korea. Korea has a high prevalence of Helicobacter pylori infections, and patients have easy accessibility to endoscopy. Therefore, we believe that guidelines regarding management of NVUGIB in Korea are essential. The Korean Society of Gastroenterology reviewed the recent evidence and recommends practical management guidelines on NVUGIB in Korea. (Gut Liver 2020;14:560-570)

Key Words: Nonvariceal upper gastrointestinal bleeding; Nonsteroidal anti-inflammatory drug; Antithrombotics; Guideline

\section{INTRODUCTION}

Nonvariceal upper gastrointestinal bleeding (NVUGIB) is one of the most common diseases and accounts for a large share of patient visits to emergency rooms. ${ }^{1}$ The development of acid suppressants, such as proton pump inhibitors (PPIs), was expected to reduce the incidence of NVUGIB. However, the prevalence of NVUGIB has not decreased with the recent increase in the use of antithrombotic and nonsteroidal anti-inflammatory drugs (NSAIDs) due to aging of the population..$^{2-4}$ Clinical practice guidelines for NVUGIB have been established and published in Europe and Asia. ${ }^{5,6}$ However, there is a limitation in applying these clinical practice guidelines in Korea because of the high prevalence of Helicobacter pylori infection, which is the main cause of NVUGIB. Patients have easy access to endoscopy in Korea compared with the West. ${ }^{7}$ The Korean College of Helicobacter and Upper Gastrointestinal Research and the Korean Society of Gastroenterology played key roles in the publication of guidelines related to the treatment of bleeding peptic ulcers in 2009. ${ }^{8}$ However, previous practice guidelines did not involve multidisciplinary participation and were closer to expert opinions than true clinical practice guidelines.

Furthermore, the guidelines did not address NVUGIB, but rather limited their recommendations to peptic ulcer bleeding. The clinical practice guidelines presented here formed recommendations via an adaptation method that complements existing practice guidelines while covering general considerations for NVUGIB as well as peptic ulcer bleeding.

The main target of these clinical guidelines is adults older than age 18 who visit a hospital due to NVUGIB. The purpose of these clinical guidelines is to make recommendations for patients with NVUGIB, classified into three time points: before endoscopy, during endoscopy, and after endoscopy. The clinical practice guidelines provide specific recommendations for effective treatment of NVUGIB patients in secondary and tertiary medical centers.

The NVUGIB guidelines are intended to clarify the definition

Correspondence to: Byung-Wook Kim

Division of Gastroenterology, Department of Internal Medicine, Incheon St. Mary's Hospital, College of Medicine, The Catholic University of Korea, 56 Dongsu-ro, Bupyeong-gu, Incheon 21431, Korea

Tel: +82-32-280-5052, Fax: +82-32-280-5987, E-mail: gastro@catholic.ac.kr

Received on May 11, 2020. Revised on June 19, 2020. Accepted on June 21, 2020.

pISSN 1976-2283 eISSN 2005-1212 https://doi.org/10.5009/gnl20154

() This is an Open Access article distributed under the terms of the Creative Commons Attribution Non-Commercial License (http://creativecommons.org/licenses/by-nc/4.0) which permits unrestricted non-commercial use, distribution, and reproduction in any medium, provided the original work is properly cited. 
of NVUGIB. First, experts discussed which patients could be defined as having NVUGIB at clinical presentation and what evaluations should initially be performed. We determine how to apply these guidelines in actual practice based on the clear definition of NVUGIB.

A patient who complains of hematemesis, melaena, or bloody stool (hematochezia) should be evaluated quickly and appropriate measures should be taken when the patient is in the hospital. Patients who present with the above symptoms are the subject of our guidelines. If the patient's medical history indicates that the patient has been diagnosed with liver cirrhosis or is strongly suspected of having liver cirrhosis, the evaluation and treatment should be planned based on variceal bleeding; thus, such patients are excluded from the indications in these guidelines. Evaluation using these guidelines can further define NVUGIB when bleeding caused by esophageal and/or gastric varices is identified and excluded.

\section{CLINICAL PRACTICE GUIDELINE DEVELOPMENT PRO- CESS}

\section{Composition of the Clinical Practice Guideline Commit-} tee and multidisciplinary participation

The Clinical Practice Guideline Committee was composed of three groups. The development steering committee established the strategy and directions for guideline development, appointed a chairperson from amongst the president and executives of the academic society, and reviewed and approved the budget. It also oversaw coordination of the stakeholders in the development of the guidelines and maintained editorial independence.

The Clinical Practice Guideline Committee was comprised of 11 gastroenterologists from 10 universities. The NVUGIB Clinical Practice Guideline Committee operated under the Korean Society of Gastroenterology and included Byung-Wook Kim, Joon Sung Kim, Do Hoon Kim, Chan Hyuk Park, Hyuk Lee, Moon Kyung Joo, Da Hyun Jung, Jun-Won Chung, and Hyuk Soon Choi. Additionally, members from the Korean College of Helicobacter and Upper Gastrointestinal Research (Gwang Ho Baik), the Korean Society of Gastrointestinal Endoscopy (Jeong Hoon Lee), the Korean Gastric Cancer Association (Kyo Young Song), and the Korean Society of Interventional Radiology (Saebeom Hur) participated in development of the clinical practice guidelines. The new guidelines were developed within the society's budget, without external financial support, and the committee developing the clinical practice guidelines operated independently of the Korean Society of Gastroenterology. Thus, the Society had no influence on the development or content of the clinical practice guidelines. All members who participated in the development maintained editorial independence by confirming that no conflicts of interest or potential interests existed and submitting such a declaration in writing. Furthermore, no conflicts of interest arose while these practice guidelines were developed. The first meeting was held in November 2018, a development workshop was held in December 2018, one Delphi vote occurred and 14 recommendations were proposed in July 2019.

\section{Development process}

The clinical practice guidelines written in Europe in 2015 and the clinical practice guidelines written in Asia in 2018 were reviewed. ${ }^{5,6}$ Since these guidelines were consistent with the scope of the guidelines to be developed in Korea and were judged to be high-quality, the decision was made to use these guidelines for the development of the new clinical guidelines. Based on the previous practice guidelines, key questions were selected and a systematic review of the literature and quality assessment were conducted to develop recommendations based on the core questions. Expert opinions were excluded as much as possible.

\section{1) Selection of key questions}

The selection of key questions for each recommendation to be included in the clinical practice guidelines was primarily done by all members of the Clinical Practice Guideline Committee. Key clinical questions for the recommendations were selected under the principles of PICO (population, intervention, comparison, and outcome). A systematic literature search was conducted based on alternative key questions for each recommendation (Table 1).

\section{2) Literature search}

The literature was searched using domestic and international databases. The foreign bibliographic databases MEDLINE, Embase, and Cochrane Library along with the domestic databases KoreaMed were searched for relevant literature published from January 1987 to November 2017. Studies that did not meet the inclusion/exclusion criteria were first eliminated based on the title and abstract of each publication, and then entire texts were carefully read to further winnow the studies that met the inclusion/exclusion criteria. In the case of a disagreement between paper reviewers, a final decision was made by a discussion of the development committee.

\section{3) Recommendation formulation, strength of the recom- mendation, and level of evidence}

Fourteen recommendations were made based on the reviewed literature. The strength of each recommendation and the level of evidence were graded using the GRADE method (Grading of Recommendations Assessment, Development, and Evaluation; http://www.gradeworkinggroup.org). Recommendation strength was classified into five levels: strongly for, weakly for, weakly against, strongly against, and insufficient (Table 1). The level of evidence was classified into four levels: high, moderate, low, and very low (Table 2). The strength of each recommendation was determined by taking into account the level of evidence 
Table 1. Strength of Recommendation

\begin{tabular}{|c|c|}
\hline Strength of recommendation & Interpretation \\
\hline Strong for & $\begin{array}{l}\text { The benefit of the intervention is greater than the harm and the level of evidence is high, which is strongly rec- } \\
\text { ommended in most clinical situations. }\end{array}$ \\
\hline Weak for & $\begin{array}{l}\text { The benefit of the intervention may vary depending on the clinical situation of the intervention or the patient/ } \\
\text { social value and is recommended to be used selectively or conditionally. }\end{array}$ \\
\hline Weak against & $\begin{array}{l}\text { The harm of the intervention may vary depending on the clinical situation of the intervention or the patient/so- } \\
\text { cial value and is recommended not to be used selectively or conditionally. }\end{array}$ \\
\hline Strong against & $\begin{array}{l}\text { The harm of the intervention is greater than the benefit and the level of evidence is high or the size of effective- } \\
\text { ness is unclear and the level of evidence is low and is recommended not to be used. }\end{array}$ \\
\hline Insufficient & $\begin{array}{l}\text { Evidence to judge the magnitude of the effectiveness of the intervention or the level of evidence is insufficient, } \\
\text { and it is not possible to decide whether or not to recommend until further research evidence is accumulated. }\end{array}$ \\
\hline
\end{tabular}

Table 2. Level of Evidence

\begin{tabular}{ll}
\hline Quality level & \multicolumn{1}{c}{ Interpretation } \\
\hline $\begin{array}{l}\text { High } \\
\text { Moderate }\end{array}$ & We are very confident that the true effect lies close to that of the estimate of the effect. \\
& possibility that it is substantially different. \\
Low & Our confidence in the effect estimate is limited. The true effect may be substantially different from the estimate of the effect. \\
Very low & We have very little confidence in the effect estimate. The true effect is likely to be substantially different from the estimate of effect.
\end{tabular}

along with the level of domestic applicability, benefits, and degree of potential harm.

\section{4) Recommendation agreement and adoption}

The recommendations derived by the Clinical Practice Guideline Committee were adopted using the Delphi technique; the voting population consisted of academic experts from the society representing the main user population of the relevant drugs. Prior to voting, the panel was sent an e-mail with recommendations and supporting documents so that the contents were read in advance and judged independently. On the day of voting, the members of the Clinical Practice Guideline Committee explained the recommendations, the evidence, and the strength of the recommendations. When the presentation was finished, an anonymous vote was conducted using an electronic keypad. The degree of consensus was classified using a 5-point Likert scale as follows: (1) strongly agree, (2) generally agree, (3) agree, (4) disagree, (5) strongly disagree. If the number of agreements in (1) and (2) combined equaled more than two-thirds of the total number of votes, the recommendation was considered to be agreed upon. As a result of the vote, 14 recommendations were passed and adopted.

\section{5) External evaluation}

The Clinical Practice Guideline Committee's steering committee appointed one person to be in charge of each recommendation; the person in charge wrote the details for the manuscript by referring to the key questions, literature review, discussion, and the results of the vote. After the draft was completed, it was reviewed by the Clinical Practice Guideline Committee and a draft was generated based on the AGREE II (Appraisal of Guidelines for Research \& Evaluation II process) criteria such that incomplete parts could be re-evaluated after correction. In order to verify the contents of the manuscript, it was evaluated by gastroenterologists (Jeong Seop Moon [Inje University], Gwang Ha Kim [Pusan National University]) who did not participate in the development process. Concerns pointed out in the peer review process were reflected in the second revision process.

\section{BODY}

Recommendation 1. Risk stratification with an appropriate scoring system prior to upper gastrointestinal endoscopy in patients with NVUGIB can predict clinical prognosis.

Grade of recommendation: strong for recommendation

Level of evidence: high quality of evidence

In order to standardize clinical decisions in the examination and treatment of patients with NVUGIB according to severity and prognosis, a scoring system was introduced to evaluate patient risk and to guide prompt and accurate treatment. Currently, the most commonly used risk assessments are the Rockall score (RS), the Glasgow-Blatchford bleeding score (GBS), and AIMS65 (Table 3).

$\mathrm{RS}^{9}$ is the most widely used scoring system. It consists of age, shock, comorbidity, and bleeding evidence. RS is effective 
Table 3. Risk Stratification Scores for Nonvariceal Upper Gastrointestinal Bleeding

\begin{tabular}{lll}
\hline \multicolumn{1}{c}{ Scoring system } & \multicolumn{1}{c}{ Clinical parameters } & Primary outcome \\
\hline GBS & BUN, hemoglobin, SBP, heart rate, comorbidity & Need intervention \\
Rockall score & Age, SBP, heart rate, comorbidity, endoscopic findings, stigmata of & Mortality \\
& recent hemorrhage & Mean length of stay/mortality \\
AIMS65 score & Albumin, PT (INR), Mental status, SBP, age &
\end{tabular}

GBS, Glasgow-Blatchford bleeding score; BUN, blood urea nitrogen; SBP, systolic blood pressure; PT, prothrombin time; INR, international normalized ratio.

at predicting the risk of re-bleeding and death. ${ }^{10,11}$ However, it has the disadvantage that application of the predictive factors is complicated and can be done only when an endoscopy is performed. Thus, scoring systems have been created to assist in the determination of emergency endoscopy or hospitalization prior to endoscopy; GBS is one of the representative scoring system. ${ }^{12}$ GBS was created to determine the need for clinical interventions, such as transfusion or emergency endoscopy, or hospitalization in patients with acute upper gastrointestinal bleeding, and to predict death. The score consists of blood urea, hemoglobin, systolic blood pressure, and pulse rate values, as well as the presence or absence of melaena, syncope, liver disease, or heart disease. A GBS score of 0 indicates that the patient is low-risk and no hospitalization or emergency endoscopy is required. ${ }^{13}$ The recently created AIMS65 is a simple scoring system that measures five risk factors: albumin level $<3.0 \mathrm{mg} / \mathrm{dL}$, INR (international normalized ratio) $>1.5$, altered mental status, systolic blood pressure $\leq 90 \mathrm{~mm} \mathrm{Hg}$, and age $>65$ years. ${ }^{14}$ The mortality rate according to AIMS65 score is $0.3 \%$ for 0 points, $1 \%$ for 1 point, 4\% for 2 points, 10\% for 3 points, $22 \%$ for 4 points, and 32\% for 5 points; a patient who scores 2 or more points is classified as high risk.

In summary, RS is effective at determining the need for hospitalization and predicting mortality and GBS is an effective indicator for predicting low-risk patients and determining the need for hospitalization and other interventions. AIMS65 is effective at predicting the need for hospitalization in an intensive care unit and mortality.

Recommendation 2. Intravenous administration of PPIs prior to upper gastrointestinal endoscopy is recommended in patients with suspected NVUGIB.

Grade of recommendation: strong for recommendation Level of evidence: high quality of evidence

Intravenous administration of PPI before endoscopy in patients with NVUGIB may reduce the need for hemostasis. PPI strongly inhibits gastric acid secretion by inhibiting stomach $\mathrm{H}+/ \mathrm{K}+-\mathrm{ATPase}$. Thus, PPI lowers the tendency to re-bleed through stabilization of the blood coagulation process by increasing intragastric $\mathrm{pH}^{15}$

Various studies have reported that there was no difference in mortality, re-bleeding rates, or need for surgery in the PPI group before endoscopy compared to the non-use group. However, high-risk findings on endoscopy were decreased and the need for endoscopic hemostasis was reduced. ${ }^{16,17}$ According to a recent meta-analysis, high-dose PPI treatment $(8 \mathrm{mg} / \mathrm{hr}$ continuous infusion for 72 hours after $80 \mathrm{mg}$ infusion) clinically reduced the re-bleeding rate, the surgical treatment rate, and the mortality rate. ${ }^{18,19}$ However, a decrease in mortality was only observed in patients with high-risk bleeding lesions who had undergone endoscopic hemostasis first, which supports the fact that PPI treatment is dependent upon endoscopic treatment and is not a substitute for intervention in these patients. ${ }^{20}$ Thus, endoscopy should not be delayed to administer PPI.

There are several opinions on appropriate PPI dosage, and several recent guidelines have reported that continuous infusion for 3 days at $8 \mathrm{mg} / \mathrm{hr}$ after a bolus infusion of $80 \mathrm{mg}$ is effective. ${ }^{21,22}$ However, recent studies have shown that intermittent dosing at $40 \mathrm{mg}$ every 12 hours after a bolus infusion of $80 \mathrm{mg}$ is similar to continuous infusion. . $^{23}$

Recommendation 3. It is recommended that upper gastrointestinal endoscopy is performed within 24 hours in patients with NVUGIB, but the timing of the procedure can be modified per the judgment of the clinician.

Grade of recommendation: strong for recommendation

Level of evidence: moderate quality of evidence

In a retrospective study of 400,000 patients who visited the hospital due to NVUGIB, the mortality rate increased if endoscopy was not performed within 24 hours. ${ }^{24}$ A recent cohort study recommended that patients who are hemodynamically unstable or American Society of Anesthesiology (ASA) 3-5 should be stabilized before undergoing endoscopic examination. ${ }^{25}$ A metaanalysis showed that performing an endoscopic examination within 12 hours did not reduce the mortality rate, the need for surgery, or the amount of blood transfusion, and only increased unnecessary endoscopic procedures. ${ }^{26}$ However, a domestic study showed that patients with GBS scores of 7 or higher who underwent endoscopies within 6 hours had reduced mortality rates, reduced blood transfusions, and a reduced need for surgery. ${ }^{27}$ Guidelines from other countries also recommend performing upper gastrointestinal endoscopies within 24 hours in patients 
with NVUGIB and state that endoscopies may be performed more quickly in high-risk patients. ${ }^{5,6}$ However, the definition of high-risk patients has not been clarified to date and, thus, is based on clinicians' judgment.

Recommendation 4. Red blood cell transfusions in patients with NVUGIB aims to achieve a hemoglobin level of 7-9 $\mathrm{g} / \mathrm{dL}$ after transfusion. In patients with comorbidities, the target hemoglobin level may be adjusted at the clinician's discretion.

Grade of recommendation: strong for recommendation

Level of evidence: moderate quality of evidence

There is concern that excessive transfusion in NVUGIB patients may increase re-bleeding and/or mortality. According to a retrospective cohort study by Restellini et $a .^{28}$ in 2013 , the risk of re-bleeding increased by $80 \%$ if a transfusion was performed within 24 hours. A retrospective cohort study by Fabricius et al. ${ }^{29}$ in 2016 showed that the risk of a second endoscopy increased by $8 \%$ and the risk of death within 30 days increased by approximately $4 \%$ whenever one unit of red blood was transfused. A subgroup analysis by Subramaniam et al. ${ }^{30}$ in 2016 showed that the effect of red blood cell transfusion may vary depending on the hemoglobin level at the time of the patient's visit. When the hemoglobin level was $7 \mathrm{~g} / \mathrm{dL}$ or $7-9 \mathrm{~g} / \mathrm{dL}$, the risk of death did not change according to red blood cell transfusions. When the hemoglobin level was $9 \mathrm{~g} / \mathrm{dL}$ at the time of the visit, the mortality rate increased by 11.9 times when four units of red blood cells were transfused, and by 15.9 times when five or more red blood cell units were transfused. In a recently published retrospective cohort study, re-bleeding and the mortality rate increased when transfusions were performed. ${ }^{31}$ These cohort studies suggest that excessive red blood cell transfusions have a negative effect on patient prognosis. Reduced blood flow in gastrointestinal bleeding patients leads to splanchnic vasoconstriction. Blood transfusions can lead to increased splanchnic blood flow and pressure, which can inhibit blood clot formation. ${ }^{32,33}$ There is also a possibility of developing clotting disorders from a blood transfusion. ${ }^{34,35}$

In a randomized study published by Villanueva et $a l .{ }^{36}$ in 2013, the 6-week survival rate was 95\% after a restrictive transfusion with a target hemoglobin level of 7-9 g/dL after transfusion. These patients had a better prognosis compared to the 91\% survival rate in cases of liberal transfusion with a target 9-11 g/dL hemoglobin level after transfusion. Re-bleeding and adverse events also occurred less frequently in cases of restrictive transfusion. Conversely, in a cluster-randomized study published by Jairath et al. ${ }^{37}$ in 2015 , restrictive transfusions tended to reduce re-bleeding and death, but the finding was not statistically significant. In a study by Jairath et al., the target hemoglobin level in restrictive transfusions was $8-10 \mathrm{~g} / \mathrm{dL}$ and the target hemoglobin level in liberal transfusions was also 8-10 $\mathrm{g} / \mathrm{dL}$, which is different from the study done by Villanueva et al. There is a possibility that a significant difference between the two groups could not be confirmed due to the difference in target hemoglobin levels. Based on these studies, it is recommended that restrictive transfusions are performed with a target hemoglobin level of 7-9 g/dL after transfusion in NVUGIB patients. However, unlike the cohort study mentioned above, the two randomized studies were conducted in patients with both NVUGIB and variceal upper gastrointestinal bleeding, and this should be considered when interpreting the results. In the study by Villanueva et al. ${ }^{36}$ which confirmed the benefit of restrictive transfusions, when subgroup analysis was performed according to the type of bleeding lesion, the mortality rate within 6 weeks with restrictive transfusion tended to decrease by $42 \%$ in the variceal bleeding group and 30\% in the nonvariceal bleeding group, but statistical significance was not achieved in either group as the sample size of each subgroup was small.

In general, it is thought that restrictive transfusions with a target hemoglobin level of 7-9 g/dL after transfusion may improve prognosis. However, restrictive transfusion with a target hemoglobin level less than $8 \mathrm{~g} / \mathrm{dL}$ in patients with underlying diseases such as cardiovascular disease may exacerbate the patient's condition. Thus, the target hemoglobin level after blood transfusion in patients with comorbidities may be adjusted by the judgment of the clinician. ${ }^{33}$

Recommendation 5. For patients with peptic ulcer bleeding, endoscopic hemostasis is determined by the Forrest classification observed during upper gastrointestinal endoscopy.

Grade of recommendation: strong for recommendation

Level of evidence: high quality of evidence

Re-bleeding from peptic ulcers can be classified into six types based on the Forrest classification, which is identified during endoscopy (Table 4). Active bleeding and visible vessels according to the Forrest classification requires endoscopic hemostasis. In particular, Forrest Ia and Ib are lesions with active bleeding and the re-bleeding rate is about 55\%. ${ }^{38} \mathrm{~A}$ previous study found that interobserver agreement is high in these lesions, and agreement on endoscopic hemostasis in these lesions was very high. ${ }^{39}$ While not active bleeding, visible

Table 4. Forrest Classification for Endoscopic Findings of Peptic Ulcer Bleeding

\begin{tabular}{ll}
\hline \multicolumn{1}{c}{ Endoscopic findings } & \multicolumn{1}{c}{ Forrest classification } \\
\hline Active bleeding & Ia (spurting or pulsatile hemorrhage) \\
& Ib (oozing hemorrhage) \\
Nonbleeding visible vessels & IIa (visible vessel) \\
Adherent clot & IIb (adherent blood clot) \\
Flat spot & IIc (flat spot, dark pigmentation) \\
Clean base & III (clean base lesion) \\
\hline
\end{tabular}


vessels (Forrest IIa) is a sign of recent bleeding and endoscopic hemostasis is required. In particular, if clear blood vessels are observed at the base of an ulcer, the re-bleeding rate is $43 \%$, and endoscopic hemostasis is also necessary. ${ }^{38}$ However, management of Forrest IIb remains controversial. ${ }^{5}$ Only 25\% of such patients experienced re-bleeding when observed for 30 days without endoscopic treatment. Patients who received endoscopic treatment had a significantly lower risk of rebleeding. However, there was no significant difference in the necessity for surgical intervention or the mortality rate. ${ }^{40}$ Thus, the judgment of the endoscopists is crucial in the case of Forrest IIb. Next, in the case of Forrest IIc and III, the re-bleeding rate was very low (5\% to 10\%), so endoscopic intervention is not necessary. ${ }^{38}$ Therefore, endoscopic treatment is not recommended for the cases of Forrest IIc and III in the "Guideline for the Treatment of Non-Bleeding Peptic Ulcer" published in Korea in 2009 or the European Society of Gastrointestinal Endoscopy (ESGE) guidelines published in 2015.

Recommendation 6. Endoscopic hemostasis is effective in Mallory-Weiss syndrome patients with active bleeding. Grade of recommendation: strong for recommendation Level of evidence: moderate quality of evidence

Mallory-Weiss syndrome, a mucosal laceration in the lower esophagus or proximal stomach, usually improves spontaneously, and endoscopic hemostasis is often unnecessary. Endoscopic therapy should be considered in cases with persistent bleeding and/or with complications. However, the syndrome may cause serious bleeding in some cases. ${ }^{41,42}$ A prospective study found that the 30-day mortality rate in Mallory-Weiss syndrome was $5.3 \%$, similar to the mortality rate in peptic ulcer bleeding. ${ }^{43}$ Clinically significant bleeding in Mallory-Weiss syndrome is associated with risk factors such as old age, coagulation disorders, underlying diseases such as portal hypertension, and active bleeding during endoscopic examination. Endoscopic hemostasis is necessary even in healthy patients without comorbidities when active bleeding, such as spurting or oozing, is observed during endoscopic examination. ${ }^{41,44-47}$ It is difficult to determine the most appropriate method for endoscopic hemostasis in Mallory-Weiss syndrome based on the current evidence. ${ }^{5}$ Among endoscopic hemostasis methods, local injection therapy is reported to be similar to other methods for the prevention of rebleeding. ${ }^{48,49}$ However, it seems to be appropriate to perform local injection therapy as a part of combined therapy rather than a monotherapy. In other reports, mechanical hemostasis, such as use of a hemoclip or band ligation, was safe and effective. ${ }^{50-53}$

Recommendation 7. Endoscopic hemostasis is recommended for patients with bleeding caused by Dieulafoy lesions.

Grade of recommendation: strong for recommendation

Level of evidence: moderate quality of evidence
Dieulafoy lesions are a rare cause of upper gastrointestinal bleeding and, in some cases, can cause massive bleeding. With the recent development of endoscopic therapy, the primary successful hemostasis rate has reached more than $90 \%{ }^{54-56}$ Endoscopic hemostasis is recommended by the ESGE guidelines published in $2018 .{ }^{21}$ Cauterization by thermal coagulation and mechanical treatment using hemostatic clips or band ligation can be performed alone or as a part of combination therapy. Recently, hemostatic clips and band ligation have been recognized as the treatments of choice for Dieulafoy lesions as they cause relatively little damage to surrounding tissues. ${ }^{57}$ According to a recent meta-analysis, the primary success rates of hemostatic clips and band ligation were high (96\% and 91\%, respectively). ${ }^{54}$ Selective arterial embolization or surgery can be advocated for cases with intractable bleeding or unsuccessful endoscopic therapy.

Recommendation 8. $H$. pylori status should be checked and, if positive, eradication therapy is recommended to prevent the recurrence of peptic ulcer bleeding.

Grade of recommendation: strong for recommendation

Level of evidence: moderate quality of evidence

H. pylori eradication therapy may reduce the recurrence of peptic ulcers, as well as in bleeding cases. ${ }^{58,59}$ The re-bleeding rate in the eradicated group was $4.5 \%$, which was significantly lower than the $23.7 \%$ seen in the acid suppressant (PPI or H2 receptor antagonist) group. ${ }^{58}$ When patients present with peptic ulcer bleeding, PPI is usually administered before endoscopy, thus lowering the sensitivity of $H$. pylori diagnosis. According to the ESGE guidelines, eradication treatment is recommended if $H$. pylori infection is confirmed in patients with peptic ulcer bleeding and re-examination should be conducted later if $H$. pylori infection is not identified in the acute phase. ${ }^{21}$ In bleeding patients, biopsy is a reliable test for $H$. pylori infection since it is not affected by PPI treatment. The timing of eradication therapy is somewhat controversial, and in general, it is often performed after the patient's condition is clinically stabilized. It is crucial to ensure that eradication therapy is successful. ${ }^{21,22}$ Additionally, there is no need for continuous administration of acid suppressants for the prevention of peptic ulcer bleeding except in cases when long-term NSAID treatment is required after eradication of $H$. pylori.

Recommendation 9. A biopsy is recommended to differentiate malignant ulcers in patients with peptic ulcer bleeding. Grade of recommendation: strong for recommendation Level of evidence: low quality of evidence

The most common cause of NVUGIB is peptic ulcer, and malignant cases are reported in $4 \%$ to $6 \%$ of patients. ${ }^{60}$ Gastric cancer is one of the most common types of cancer in Korea. It is crucial to observe the lesion thoroughly by endoscopy. It is also 
essential to conduct a biopsy for suspected lesions to ensure an accurate diagnosis. If a biopsy was not performed at the time of the initial endoscopy, immediate endoscopic re-examination along with biopsy is recommended when gastric cancer is highly suspected. Additionally, it is crucial to exclude gastric cancer through endoscopic re-examination after medical treatment, even if the initial diagnosis was benign.

Recommendation 10. PPI administration is recommended to prevent re-bleeding in patients with NVUGIB.

Grade of recommendation: strong for recommendation

Level of evidence: high quality of evidence

Many studies have examined the effects of PPI in patients with NVUGIB. A Cochrane review of 24 randomized controlled trials including 4,373 patients reported that PPI administration significantly reduced re-bleeding ( $10.6 \%$ vs $17.3 \%$ : odds ratio [OR], 0.49; 95\% confidence interval [CI], 0.37 to 0.65$)$ and avoided additional surgery (6.1\% vs 9.3\%: OR, 0.61; 95\% CI, 0.48 to 0.78 ) compared to placebo or $\mathrm{H}_{2}$ receptor inhibitors. However, PPI administration did not reduce the mortality rate. Subgroup analysis revealed that PPI administration significantly reduced re-bleeding within 3 days, continuous bleeding, surgical treatment, additional endoscopic procedures, and transfusions. ${ }^{61}$ Based on these results, we recommend administration of PPI to prevent re-bleeding in patients with NVUGIB.

A meta-analysis in 2009 showed that intravenous administration (intravenous injection lasting 72 hours at $8 \mathrm{mg}$ per hour after a single intravenous injection of $80 \mathrm{mg}$ ) of high-dose PPI after endoscopic hemostasis in NVUGIB patients significantly reduced re-bleeding (relative risk [RR], 0.40; 95\% CI, 0.28 to 0.59 ; minimum number of patients 12 ), additional surgery (RR, 0.43; 95\% CI, 0.24 to 0.76; minimum number of patients 28), and mortality (RR, 0.41 ; 95\% CI, 0.20 to 0.84 ; minimum number of treated patients 45) compared to placebo or $\mathrm{H}_{2}$ receptor inhibitors. ${ }^{19}$ Based on this evidence, the existing guidelines of the International Consensus Upper Gastrointestinal Bleeding Conference Group, ${ }^{62}$ American College of Gastroenterology, ${ }^{22}$ and $\mathrm{ESGE}^{5}$ recommend that patients with NVUGIB be injected intravenously with $80 \mathrm{mg}$ PPI once after endoscopic hemostasis, followed by intravenous injection of $8 \mathrm{mg}$ per hour for 72 hours. Also, studies comparing continuous intravenous injections for 3 days after a single intravenous injection and intermittent dosing for 3 days have been conducted. In a metaanalysis of these studies, the relative risk of re-bleeding within 7 days of intermittent dosing and continuous injections after a single intravenous injection was 0.72 (95\% CI, upper limit 0.97 ) and the absolute risk difference was $-2.64 \%$ (95\% CI, upper limit -0.28). Intermittent administration of PPI showed the same effect as continuous injections after a single intravenous injection. ${ }^{23}$ In addition, two randomized controlled studies have recently been published comparing oral administration of high doses of PPI for 3 days and continuous intravenous injections for 3 days after a single intravenous injection. These studies found no significant differences between the two groups in rebleeding, additional surgery, transfusion volume, or mortality rate. ${ }^{63,64}$ However, both of these studies were conducted in the East, so there is a limit to the generalization of the results to other races and regions.

Recommendation 11. Second-look endoscopy is defined as endoscopic examination performed within 1 to 2 days after endoscopic hemostasis. Conventional second-look endoscopy is not recommended for patients with NVUGIB. However, if the risk of re-bleeding is high, second-look endoscopy may be considered.

Grade of recommendation: moderate for recommendation

Level of evidence: moderate quality of evidence

In general, second-look endoscopy is not recommended to lower the risk of re-bleeding. Second-look endoscopy is also not recommended in the ESGE guidelines published in 2015 . $^{5} \mathrm{Sec}-$ ond-look endoscopy is defined as endoscopy performed within 1 to 2 days after initial hemostasis to reduce the risk of clinically significant re-bleeding. A meta-analysis showed that secondlook endoscopy lowered re-bleeding and reduced the need for emergency surgery. However, this meta-analysis included only one study that used high-dose PPI, which limits its relevance in this era of routine high-dose PPI. ${ }^{65}$ In addition, second-look endoscopy is not necessary because it is not cost-effective. ${ }^{66}$ However, if there is a high risk of re-bleeding, such as unstable vital signs, active bleeding, and/or a large ulcer, second-look endoscopy may be considered. ${ }^{2}$

Recommendation 12. In patients with NVUGIB who were taking antiplatelet agents or anticoagulants, re-administration of antiplatelet agents or anticoagulants should be started as soon as possible after hemostasis.

Grade of recommendation: moderate for recommendation

Level of evidence: moderate quality of evidence

Patients who take antithrombotic drugs, such as antiplatelet agents or anticoagulants, are associated with increased risk of thrombo-embolic events when the medication is halted. According to a meta-analysis of six prospective cohort studies by Biondi-Zoccai et al., ${ }^{67}$ the risk of thrombo-embolic events increased 3.1-fold when aspirin was discontinued in cardiovascular patients. Thus, patients taking antithrombotic agents to prevent cardiovascular disease should resume medication as soon as possible after hemostasis. The risk of re-bleeding may increase if the patient takes the antithrombotic agent again. According to a randomized study by Sung et al.$^{68}$ in 2010, the risk of re-bleeding increased by a statistically insignificant 1.9 times in patients with peptic ulcer bleeding who took aspirin when 
endoscopic hemostasis was performed and aspirin was maintained after PPI administration. On the contrary, if aspirin was maintained after hemostasis, the cardiovascular-related mortality rate and overall mortality rate were reduced by $80 \%$ compared to cases in which aspirin was stopped for 8 weeks. In a retrospective cohort study by Derogar et al. ${ }^{69}$ in 2013, the risk of death increased when aspirin was discontinued in patients with peptic ulcer bleeding. Specifically, the risk of death increased in patients within 6 months of discontinuing aspirin. Also, when the subjects were divided into an aspirin maintenance group, an aspirin resumption group within 30 days, and a non-resumption group, aspirin resumption had no significant effect on the risk of death compared to aspirin maintenance. However, if aspirin was not resumed within 30 days, the risk of death increased by $75 \%$ compared to the aspirin maintenance group.

For patients undergoing dual antiplatelet therapy after coronary stent insertion, there is a concern about the occurrence of stent thrombosis when antithrombotic agents are discontinued. There is no clear evidence regarding when to resume medication in these patients. However, Eisenberg et al. ${ }^{70}$ conducted a systematic literature review for articles on stent thrombosis and selected and analyzed a total of 19 cases of stent thrombosis. The results showed that it seems to be safe to maintain aspirin in patients receiving dual antiplatelet therapy. Among patients with stent thrombosis, obstruction occurred in a median of 7 days in patients who stopped both aspirin and thienopyridine, whereas obstruction occurred in a median of 112 days in patients who maintained aspirin. Thus, even if thienopyridine is discontinued because of gastrointestinal bleeding, maintaining aspirin may lower the risk of stent thrombosis.

There is insufficient evidence to recommend a specific timeline for re-administration of antithrombotic drugs to patients with NVUGIB. However, if endoscopic hemostasis is successful, aspirin should be resumed immediately. If the patient had been taking other antithrombotic drugs, such as thienopyridine, alternative administration of aspirin should be considered before resuming antithrombotics.

Recommendation 13. Transarterial embolization (TAE) may be a priority for patients with NVUGIB in whom an upper gastrointestinal endoscopy cannot be performed or in patients who failed endoscopic hemostasis.

Grade of recommendation: strong for recommendation

Level of evidence: moderate quality of evidence

TAE can be considered as a treatment option in patients with NVUGIB when endoscopy cannot be performed, when endoscopic hemostasis has failed, or when re-bleeding occurred after successful endoscopic hemostasis. ${ }^{71}$ Prospective randomized trials comparing surgery and TAE have not been conducted so far. In a series of retrospective observational reports and metaanalyses, surgery was associated with lower bleeding rates. How- ever, the common conclusion was that there was no difference in mortality between the two groups. ${ }^{71}$ This is because repetitive procedures are possible with TAE even with re-bleeding, and there are fewer complications related to TAE than surgery. In the above-mentioned meta-analysis, the ratio of coagulation factor abnormalities from ischemic heart disease was higher in the patients who underwent TAE than in the patients who underwent surgery. This finding can be explained by noting that even patients who were unsuitable for surgery could receive TAE. ${ }^{72}$

NVUGIB cases that require surgery or TAE often necessitate immediate emergency procedures, and it is difficult to obtain high-level evidence from randomized trials because of differences in the indications for the two treatment modalities. However, as the technological factors associated with TAE, such as the angiography device, microcatheter and catheter, and embolic material, continue to improve, the implementation of TAE is becoming more common globally. ${ }^{71,73}$ Thus, TAE may be considered as a secondary alternative treatment for endoscopic hemostasis in patients with NVUGIB in a medical environment with easy access to emergency TAE, such as Korea.

Recommendation 14. Surgical treatment may be considered for re-bleeding or failure of endoscopic hemostasis in patients with NVUGIB.

Grade of recommendation: strong for recommendation

Level of evidence: low quality of evidence

Despite progress in endoscopic treatment methods, some patients with NVUGIB still require surgery for hemostasis. ${ }^{74}$ However, it is difficult to determine which patients will not respond to endoscopic treatment, and there is controversy regarding when to perform surgery. Shock and low hemoglobin levels are the main clinical factors that indicate a need for surgery. Forrest classification during endoscopy is the most accurate indicator of recurrence, but the location and size of the ulcer are also critical. An ulcer larger than $2 \mathrm{~cm}$, duodenal ulcers located at the posterior wall, and gastric ulcers carry significantly higher risks of re-bleeding, ${ }^{75,76}$ and patients with these characteristics may require close monitoring and surgical treatment as soon as possible. The indications for surgery are traditionally based on transfusion requirements, as transfusion volume is associated with increased mortality rates. When transfusion requirements exceed six units in elderly patients or when eight to 10 units are required in young patients, surgical treatment should be considered. Secondary or relative indications include rare blood types, transfusion rejection, a state of shock, elderly age, severe comorbidity, and chronic gastric ulcer bleeding.

The primary goal of surgery is hemostasis. Once hemostasis is achieved, it is necessary to decide whether to perform additional anti-ulcer surgery to reduce acid secretion. The method of surgery depends on whether the lesion is in the stomach or the duodenum. 


\section{CONCLUSION}

NVUGIB is a disease with a high prevalence and high mortality rate, and it accounts for a large proportion of patients visiting the emergency room. However, there have been no evidence-based clinical practice guidelines with multidisciplinary participation related to the treatment of NVUGIB in Korea. In this guideline, recommendations related to patient assessment and treatment before an endoscopic procedure, treatment during and after an endoscopic procedure, and patient management after a procedure are made for patients who visit the hospital with NVUGIB. Our recommendations are intended to assist clinicians in identifying NVUGIB patients and provide guidelines on the timing and treatment methods of endoscopy as well as the management and treatment with drugs after endoscopic procedures. These clinical practice guidelines are intended to serve as a medical care guide for medical practitioners that will aid in providing patients with the best clinical treatment.

\section{CONFLICTS OF INTEREST}

No potential conflict of interest relevant to this article was reported.

\section{ACKNOWLEDGEMENTS}

This guideline has been published jointly with consent in both the Gut and Liver and The Korean Journal of Gastroenterology.

\section{ORICD}

Joon Sung Kim

Byung-Wook Kim

Do Hoon Kim

Chan Hyuk Park

Hyuk Lee

Moon Kyung Joo

Da Hyun Jung

Jun-Won Chung

Hyuk Soon Choi

Gwang Ho Baik

Jeong Hoon Lee

Kyo Young Song

Saebeom Hur

\section{REFERENCES}

1. Laine L. Clinical practice: upper gastrointestinal bleeding due to a peptic ulcer. N Engl J Med 2016;374:2367-2376.

2. Laine L, Yang H, Chang SC, Datto C. Trends for incidence of hospitalization and death due to GI complications in the United States from 2001 to 2009. Am J Gastroenterol 2012;107:1190-1195.
3. Quan S, Frolkis A, Milne K, et al. Upper-gastrointestinal bleeding secondary to peptic ulcer disease: incidence and outcomes. World J Gastroenterol 2014;20:17568-17577.

4. Tielleman T, Bujanda D, Cryer B. Epidemiology and risk factors for upper gastrointestinal bleeding. Gastrointest Endosc Clin N Am 2015;25:415-428.

5. Gralnek IM, Dumonceau JM, Kuipers EJ, et al. Diagnosis and management of nonvariceal upper gastrointestinal hemorrhage: European Society of Gastrointestinal Endoscopy (ESGE) Guideline. Endoscopy 2015;47:a1-a46.

6. Sung JJ, Chiu PW, Chan FKL, et al. Asia-Pacific working group consensus on non-variceal upper gastrointestinal bleeding: an update 2018. Gut 2018;67:1757-1768.

7. Lee JH, Choi KD, Jung HY, et al. Seroprevalence of Helicobacter pylori in Korea: a multicenter, nationwide study conducted in 2015 and 2016. Helicobacter 2018;23:e12463.

8. Chung IK, Lee DH, Kim HU, et al. Guidelines of treatment for bleeding peptic ulcer disease. Korean J Gastroenterol 2009;54:298308.

9. Rockall TA, Logan RF, Devlin HB, Northfield TC. Risk assessment after acute upper gastrointestinal haemorrhage. Gut 1996;38:316321.

10. Wang CY, Qin J, Wang J, Sun CY, Cao T, Zhu DD. Rockall score in predicting outcomes of elderly patients with acute upper gastrointestinal bleeding. World J Gastroenterol 2013;19:3466-3472.

11. Cieniawski D, Kuźniar E, Winiarski M, Matłok M, Kostarczyk W, Pedziwiatr M. Prognostic value of the Rockall score in patients with acute nonvariceal bleeding from the upper gastrointestinal tract. Przegl Lek 2013;70:1-5.

12. Blatchford O, Davidson LA, Murray WR, Blatchford M, Pell J. Acute upper gastrointestinal haemorrhage in west of Scotland case ascertainment study. BMJ 1997;315:510-514.

13. Stanley AJ, Ashley D, Dalton HR, et al. Outpatient management of patients with low-risk upper-gastrointestinal haemorrhage: multicenter validation and prospective evaluation. Lancet 2009;373:4247.

14. Saltzman JR, Tabak YP, Hyett BH, Sun X, Travis AC, Johannes RS. A simple risk score accurately predicts in-hospital mortality, length of stay, and cost in acute upper GI bleeding. Gastrointest Endosc 2011;74:1215-1224.

15. Green FW Jr, Kaplan MM, Curtis LE, Levine PH. Effect of acid and pepsin on blood coagulation and platelet aggregation. A possible contributor prolonged gastroduodenal mucosal hemorrhage. Gastroenterology 1978;74:38-43.

16. Lau JY, Leung WK, Wu JC, et al. Omeprazole before endoscopy in patients with gastrointestinal bleeding. N Engl J Med 2007;356:1631-1640

17. Sreedharan A, Martin J, Leontiadis GI, et al. Proton pump inhibitor treatment initiated prior to endoscopic diagnosis in upper gastrointestinal bleeding. Cochrane Database Syst Rev 2010;2010:CD005415.

18. Bardou M, Toubouti Y, Benhaberou-Brun D, Rahme E, Barkun AN. 
Meta-analysis: proton-pump inhibition in high-risk patients with acute peptic ulcer bleeding. Aliment Pharmacol Ther 2005;21:677686.

19. Laine L, McQuaid KR. Endoscopic therapy for bleeding ulcers: an evidence-based approach based on meta-analyses of randomized controlled trials. Clin Gastroenterol Hepatol 2009;7:33-47.

20. Jensen DM, Pace SC, Soffer E, Comer GM; 315 Study Group. Continuous infusion of pantoprazole versus ranitidine for prevention of ulcer rebleeding: a U.S. multicenter randomized, double-blind study. Am J Gastroenterol 2006;101:1991-1999.

21. Karstensen JG, Ebigbo A, Aabakken L, et al. Nonvariceal upper gastrointestinal hemorrhage: European Society of Gastrointestinal Endoscopy (ESGE) Cascade Guideline. Endosc Int Open 2018;6:E1256-E1263.

22. Laine L, Jensen DM. Management of patients with ulcer bleeding. Am J Gastroenterol 2012;107:345-360.

23. Sachar H, Vaidya K, Laine L. Intermittent vs continuous proton pump inhibitor therapy for high-risk bleeding ulcers: a systematic review and meta-analysis. JAMA Intern Med 2014;174:17551762.

24. Wysocki JD, Srivastav S, Winstead NS. A nationwide analysis of risk factors for mortality and time to endoscopy in upper gastrointestinal haemorrhage. Aliment Pharmacol Ther 2012;36:30-36.

25. Laursen SB, Leontiadis GI, Stanley AJ, Møller MH, Hansen JM, Schaffalitzky de Muckadell OB. Relationship between timing of endoscopy and mortality in patients with peptic ulcer bleeding: a nationwide cohort study. Gastrointest Endosc 2017;85:936-944.

26. Tsoi KK, Ma TK, Sung JJ. Endoscopy for upper gastrointestinal bleeding: how urgent is it? Nat Rev Gastroenterol Hepatol 2009;6:463-469.

27. Cho SH, Lee YS, Kim YJ, et al. Outcomes and role of urgent endoscopy in high-risk patients with acute nonvariceal gastrointestinal bleeding. Clin Gastroenterol Hepatol 2018;16:370-377.

28. Restellini S, Kherad O, Jairath V, Martel M, Barkun AN. Red blood cell transfusion is associated with increased rebleeding in patients with nonvariceal upper gastrointestinal bleeding. Aliment Pharmacol Ther 2013;37:316-322.

29. Fabricius R, Svenningsen P, Hillingsø J, Svendsen LB, Sillesen M. Effect of transfusion strategy in acute non-variceal upper gastrointestinal bleeding: a nationwide study of 5861 hospital admissions in Denmark. World J Surg 2016;40:1129-1136.

30. Subramaniam K, Spilsbury K, Ayonrinde OT, et al. Red blood cell transfusion is associated with further bleeding and fresh-frozen plasma with mortality in nonvariceal upper gastrointestinal bleeding. Transfusion 2016;56:816-826.

31. Hajiagha Mohammadi AA, Reza Azizi M. Prognostic factors in patients with active non-variceal upper gastrointestinal bleeding. Arab J Gastroenterol 2019;20:23-27.

32. Roberts I, Evans P, Bunn F, Kwan I, Crowhurst E. Is the normalisation of blood pressure in bleeding trauma patients harmful? Lancet 2001;357:385-387.

33. Duggan JM. Review article: transfusion in gastrointestinal haem- orrhage. If, when and how much? Aliment Pharmacol Ther 2001;15:1109-1113.

34. Blair SD, Janvrin SB, McCollum CN, Greenhalgh RM. Effect of early blood transfusion on gastrointestinal haemorrhage. Br J Surg 1986;73:783-785.

35. Hearnshaw SA, Logan RF, Palmer KR, Card TR, Travis SP, Murphy MF. Outcomes following early red blood cell transfusion in acute upper gastrointestinal bleeding. Aliment Pharmacol Ther 2010;32:215-224.

36. Villanueva C, Colomo A, Bosch A, et al. Transfusion strategies for acute upper gastrointestinal bleeding. N Engl J Med 2013;368:1121.

37. Jairath V, Kahan BC, Gray A, et al. Restrictive versus liberal blood transfusion for acute upper gastrointestinal bleeding (TRIGGER): a pragmatic, open-label, cluster randomised feasibility trial. Lancet 2015;386:137-144.

38. Laine L, Peterson WL. Bleeding peptic ulcer. N Engl J Med 1994;331:717-727.

39. Lau JY, Sung JJ, Chan AC, et al. Stigmata of hemorrhage in bleeding peptic ulcers: an interobserver agreement study among international experts. Gastrointest Endosc 1997;46:33-36.

40. Bleau BL, Gostout CJ, Sherman KE, et al. Recurrent bleeding from peptic ulcer associated with adherent clot: a randomized study comparing endoscopic treatment with medical therapy. Gastrointest Endosc 2002;56:1-6.

41. Kim HS. Endoscopic management of mallory-weiss tearing. Clin Endosc 2015;48:102-105.

42. Harris JM, DiPalma JA. Clinical significance of Mallory-Weiss tears. Am J Gastroenterol 1993;88:2056-2058.

43. Ljubičič N, Budimir I, Pavič T, et al. Mortality in high-risk patients with bleeding Mallory-Weiss syndrome is similar to that of peptic ulcer bleeding. Results of a prospective database study. Scand J Gastroenterol 2014;49:458-464.

44. Chung IK, Kim EJ, Hwang KY, et al. Evaluation of endoscopic hemostasis in upper gastrointestinal bleeding related to MalloryWeiss syndrome. Endoscopy 2002;34:474-479.

45. Bharucha AE, Gostout CJ, Balm RK. Clinical and endoscopic risk factors in the Mallory-Weiss syndrome. Am J Gastroenterol 1997;92:805-808.

46. Kortas DY, Haas LS, Simpson WG, Nickl NJ 3rd, Gates LK Jr. Mallory-Weiss tear: predisposing factors and predictors of a complicated course. Am J Gastroenterol 2001;96:2863-2865.

47. Kim JW, Kim HS, Byun JW, et al. Predictive factors of recurrent bleeding in Mallory-Weiss syndrome. Korean J Gastroenterol 2005;46;447-454.

48. Park $\mathrm{CH}$, Min SW, Sohn YH, et al. A prospective, randomized trial of endoscopic band ligation vs. epinephrine injection for actively bleeding Mallory-Weiss syndrome. Gastrointest Endosc 2004;60:22-27.

49. Huang SP, Wang HP, Lee YC, et al. Endoscopic hemoclip placement and epinephrine injection for Mallory-Weiss syndrome with active bleeding. Gastrointest Endosc 2002;55:842-846. 
50. Lee S, Ahn JY, Jung HY, et al. Effective endoscopic treatment of Mallory-Weiss syndrome using Glasgow-Blatchford score and Forrest classification. J Dig Dis 2016;17:676-684.

51. Lecleire S, Antonietti M, Iwanicki-Caron I, et al. Endoscopic band ligation could decrease recurrent bleeding in Mallory-Weiss syndrome as compared to haemostasis by hemoclips plus epinephrine. Aliment Pharmacol Ther 2009;30:399-405.

52. Shimoda R, Iwakiri R, Sakata H, et al. Endoscopic hemostasis with metallic hemoclips for iatrogenic Mallory-Weiss tear caused by endoscopic examination. Dig Endosc 2009;21:20-23.

53. Saltzman JR, Strate LL, Di Sena V, et al. Prospective trial of endoscopic clips versus combination therapy in upper GI bleeding (PROTECCT--UGI bleeding). Am J Gastroenterol 2005;100:15031508.

54. Barakat M, Hamed A, Shady A, Homsi M, Eskaros S. Endoscopic band ligation versus endoscopic hemoclip placement for Dieulafoy's lesion: a meta-analysis. Eur J Gastroenterol Hepatol 2018;30:995-996.

55. Senger JL, Kanthan R. The evolution of Dieulafoy's lesion since 1897: then and now-a journey through the lens of a pediatric lesion with literature review. Gastroenterol Res Pract 2012;2012:432517.

56. Baxter M, Aly EH. Dieulafoy's lesion: current trends in diagnosis and management. Ann R Coll Surg Engl 2010;92:548-554.

57. Chung IK, Kim EJ, Lee MS, et al. Bleeding Dieulafoy's lesions and the choice of endoscopic method: comparing the hemostatic efficacy of mechanical and injection methods. Gastrointest Endosc 2000;52:721-724.

58. Gisbert JP, Khorrami S, Carballo F, Calvet X, Gene E, DominguezMuñoz E. Meta-analysis: Helicobacter pylori eradication therapy vs. antisecretory non-eradication therapy for the prevention of recurrent bleeding from peptic ulcer. Aliment Pharmacol Ther 2004;19:617-629.

59. Huang TC, Lee CL. Diagnosis, treatment, and outcome in patients with bleeding peptic ulcers and Helicobacter pylori infections. Biomed Res Int 2014;2014:658108.

60. Samuel R, Bilal M, Tayyem 0, Guturu P. Evaluation and management of non-variceal upper gastrointestinal bleeding. Dis Mon 2018;64:333-343.

61. Leontiadis GI, Sharma VK, Howden CW. Proton pump inhibitor treatment for acute peptic ulcer bleeding. Cochrane Database Syst Rev 2006;(1):CD002094.

62. Barkun AN, Bardou M, Kuipers EJ, et al. International consensus recommendations on the management of patients with nonvariceal upper gastrointestinal bleeding. Ann Intern Med 2010;152:101113.

63. Kim HK, Kim JS, Kim TH, et al. Effect of high-dose oral rabepra- zole on recurrent bleeding after endoscopic treatment of bleeding peptic ulcers. Gastroenterol Res Pract 2012;2012:317125.

64. Sung JJ, Suen BY, Wu JC, et al. Effects of intravenous and oral esomeprazole in the prevention of recurrent bleeding from peptic ulcers after endoscopic therapy. Am J Gastroenterol 2014;109:1005-1010.

65. El Ouali S, Barkun AN, Wyse J, et al. Is routine second-look endoscopy effective after endoscopic hemostasis in acute peptic ulcer bleeding? A meta-analysis. Gastrointest Endosc 2012;76:283-292.

66. Imperiale TF, Kong N. Second-look endoscopy for bleeding peptic ulcer disease: a decision-effectiveness and cost-effectiveness analysis. J Clin Gastroenterol 2012;46:e71-e75.

67. Biondi-Zoccai GG, Lotrionte M, Agostoni P, et al. A systematic review and meta-analysis on the hazards of discontinuing or not adhering to aspirin among 50,279 patients at risk for coronary artery disease. Eur Heart J 2006;27:2667-2674.

68. Sung JJ, Lau JY, Ching JY, et al. Continuation of low-dose aspirin therapy in peptic ulcer bleeding: a randomized trial. Ann Intern Med 2010;152:1-9.

69. Derogar M, Sandblom G, Lundell L, et al. Discontinuation of lowdose aspirin therapy after peptic ulcer bleeding increases risk of death and acute cardiovascular events. Clin Gastroenterol Hepatol 2013;11:38-42.

70. Eisenberg MJ, Richard PR, Libersan D, Filion KB. Safety of shortterm discontinuation of antiplatelet therapy in patients with drugeluting stents. Circulation 2009;119:1634-1642.

71. Hur S, Jae HJ, Lee H, Lee M, Kim HC, Chung JW. Superselective embolization for arterial upper gastrointestinal bleeding using nbutyl cyanoacrylate: a single-center experience in 152 patients. J Vasc Interv Radiol 2017;28:1673-1680.

72. Beggs AD, Dilworth MP, Powell SL, Atherton H, Griffiths EA. A systematic review of transarterial embolization versus emergency surgery in treatment of major nonvariceal upper gastrointestinal bleeding. Clin Exp Gastroenterol 2014;7:93-104.

73. Loffroy R, Estivalet L, Cherblanc V, et al. Transcatheter embolization as the new reference standard for endoscopically unmanageable upper gastrointestinal bleeding. World J Gastrointest Surg 2012;4:223-227.

74. Wang YR, Richter JE, Dempsey DT. Trends and outcomes of hospitalizations for peptic ulcer disease in the United States, 1993 to 2006. Ann Surg 2010;251:51-58.

75. Guglielmi A, Ruzzenente A, Sandri M, et al. Risk assessment and prediction of rebleeding in bleeding gastroduodenal ulcer. Endoscopy 2002;34:778-786.

76. Chung IK, Kim EJ, Lee MS, et al. Endoscopic factors predisposing to rebleeding following endoscopic hemostasis in bleeding peptic ulcers. Endoscopy 2001;33:969-975. 